Revista de Economia Política, vol. 28, $n^{\circ} 3$ (111), pp. 434-442, julho-setembro/2008

\title{
Câmbio, especulação e juros no modelo da Teoria Geral
}

JOÃO SICSÚ*

Exchange, speculation and interest in the General Theory model. This short chapter aims to make an adaptation to a small and financially integrated economy of the monetary / financial model presented by J. M. Keynes in his General Theory of Employment, interest and money. So, this has as a goal, particularly, to adapt the chapters 15 and 17 of the General Theory basically concerned to the speculative motivations to define the composition of the assets portfolio. Theory

Keywords: interest and exchange rates; speculative motivation; Keynes's General

JEL: E12 - E43 - E41

\section{INTRODUÇÃO}

Este pequeno artigo objetiva fazer uma adaptação para uma economia pequena e financeiramente integrada do modelo monetário/financeiro apresentado por J.M.Keynes em sua Teoria Geral do Emprego, do Juro e da Moeda (doravante, apenas Teoria Geral). Objetiva-se, particularmente, fazer uma adaptação dos capítulos 15 e 17 da Teoria Geral no que diz respeito basicamente às motivações especulativas para a composição de carteiras de ativos. No capítulo 15, Keynes descreveu de forma detalhada os motivos que levam os agentes a demandar liquidez pelo motivo especulação, assim como relacionou tais incentivos com o processo de determinação da taxa de juros. No capítulo 17, apresentou um modelo de composição de portfólio onde destacou os atributos que determinam a atratividade de ativos que possuem graus de liquidez diferenciados.

\footnotetext{
* Professor do Instituto de Economia da UFRJ e pesquisador do CNPq, e-mail: jsicsu@terra.com.br. O autor agradece os comentários e elogios de Julio Lopez G. e Fernando Ferrari a uma versão anterior do presente artigo. Cabe, no entanto, eximi-los de quaisquer responsabilidades sobre esta versão final. Submetido: Fevereiro 2006; Aprovado Fevereiro 2007.
} 
As principais conclusões do modelo aplicado a uma economia pequena e financeiramente aberta são: (i) a taxa de juros é o prêmio pago pelos agentes para abrir mão dos ativos líquidos que possuem (tal como no modelo original da Teoria Geral), (ii) touros e ursos são capazes de ter grande influência na determinação da taxa de câmbio, (iii) governos perdem autonomia para determinar a taxa de juros e (iv) a política monetária é vista com reservas como instrumento para controlar a taxa de câmbio. Por último, cabe ser observado que o pequeno artigo não objetiva polemizar com outras interpretações existentes sobre o tema, especialmente, com a teoria da paridade de juros.

\section{PREFERÊNCIA PELA LIQUIDEZ EM UMA ECONOMIA PEQUENA E FINANCEIRAMENTE ABERTA}

1) No modelo de demanda por liquidez apresentado por Keynes na sua Teoria Geral, o motivo especulação é, em uma economia fechada, função da expectativa da taxa de juros que remunera títulos do tipo perpétuos. O risco de default é desconsiderado, o governo é considerado bom pagador, sempre.

2) Em uma economia pequena, financeiramente integrada e com movimentação de capital suficiente para alterar a sua taxa de câmbio, a demanda por liquidez é feita por global players. É importante ressaltar que global players não são apenas os não-residentes que podem levar ou retirar capital do país, mas também os residentes que podem realizar tais movimentações.

3) Global players compõem a sua carteira com quatro ativos adquiridos no mercado internacional e em economias pequenas e financeiramente abertas: (i) títulos sem risco de default, (ii) dólares, (iii) moeda doméstica e (iv) títulos domésticos (com risco de default). A única motivação dos global players para demandar moeda doméstica de um país qualquer com uma economia pequena e financeiramente integrada advém da regra institucional que obriga a aquisição de títulos domésticos e dólares com moeda doméstica. A moeda doméstica, para os global players, é apenas um meio transacional/financeiro em uma economia com essas características. A motivação para adquirir dólares está baseada na proteção que este ativo possui (é livre de risco) e na sua capacidade de adquirir o ativo livre de risco que possui rentabilidade que são títulos públicos, por exemplo, do Tesouro americano. Os quatro ativos com suas respectivas rentabilidades e riscos estão listados na tabela a seguir.

\begin{tabular}{l|l|l}
\hline \multicolumn{1}{c|}{ Ativos } & \multicolumn{1}{|c}{ Rentabilidade [q] } & \multicolumn{1}{c}{ Risco $[\mathrm{r}]$} \\
\hline 1) Moeda doméstica & nula & positivo $\left[d=\left(E^{\mathrm{e}}-\mathrm{E}\right) / \mathrm{E}\right]$ \\
2) Título doméstico & positiva $[++]$ & positivo $[\beta]$ \\
3) Dólar & nula & nulo \\
4) Título Livre de Risco & positiva $[+]$ & nulo \\
\hline
\end{tabular}

Nota: o sinal ++ indica que a rentabilidade dos títulos domésticos é maior que a rentabilidade dos títulos livre de risco que apresenta o sinal + . O risco de carregamento da moeda doméstica expresso na fórmula $d=\left(E^{e}-E\right) / E$, assim como $\beta$, o risco de carregamento de títulos domésticos, serão explicados logo a seguir. 
4) Três variáveis influenciam as decisões de carteira de global players: diferencial de juros; expectativa cambial e risco de default. Por quê? E como?

4.1) O diferencial de juros doméstico e internacional é a rentabilidade que atrai capitais e que, portanto, explica os seus movimentos. Em situações de calmaria, os juros, tanto doméstico quanto internacional, são considerados dados, já que suas variações são tidas como previsíveis ou incapazes de influenciar de forma decisiva a rentabilidade de portfólios em curto espaço de tempo. Os títulos domésticos mantêm o seu valor de mercado, exceto em situações extremas em que se espera um default.

4.2) A obrigação institucional de o investidor internacional adentrar um país com dólares, mas ter de convertê-lo em moeda doméstica para, só então, comprar títulos domésticos, impõe a mesma rota em sentido inverso no momento da saída. Esta obrigação institucional introduz uma variável crucial no modelo: a expectativa cambial, já que, durante o tempo de permanência do capital no país, a taxa de câmbio pode se desvalorizar. A expectativa cambial (moeda doméstica-dólar) pode ser considerada como um componente importante do risco de carregamento de um ativo denominado em moeda doméstica, já que pode impor um custo de transação para aquele que deseja obter liquidez máxima, ou risco zero, em um ambiente financeiramente globalizado. Tal risco pode ser representado pela seguinte fórmula $\mathrm{d}=\left(\mathrm{E}^{\mathrm{e}}-\mathrm{E}\right) / \mathrm{E}$, onde $\mathrm{E}$ é a taxa de câmbio no momento da entrada $\mathrm{e}$ $\mathrm{E}^{e}$ é a taxa de câmbio esperada para o momento da saída. Assim como a inflação retira liquidez da moeda em uma economia fechada (já que impõe um custo de transação à moeda), a desvalorização cambial retira liquidez da moeda em uma economia financeiramente integrada. Em verdade, este também representa um risco para quem detém títulos domésticos porque o trâmite institucional mencionado anteriormente obriga tal detentor a comprar moeda doméstica como um pedágio (um custo de transação) para adquirir a liquidez dos ativos com risco nulo. Em outras palavras, o pedágio para atravessar as fronteiras pode ter o seu preço aumentado durante o período de permanência de um viajante em um determinado país, ou seja, o preço do ticket de saída pode se tornar maior que o de entrada.

4.3) O risco de carregamento de um título doméstico $(\beta)$ é a possibilidade de realizá-lo (vendê-lo) a um preço diferente do preço de aquisição em mercado secundário ou perante seu emissor (em caso de reestruturação da dívida interna); o risco de default é uma medida do grau de risco de um emprestador devido a uma performance por parte do emissor que pode reduzir o preço do título.

5) Segundo o modelo do capítulo 17 da Teoria Geral, dos atributos de um ativo destacados por Keynes, o prêmio de risco e a rentabilidade esperada são os quesitos relevantes que explicam a demanda dos quatro ativos mencionados. Ainda segundo o capítulo 17, o retorno total esperado (RTE) do ativo será a sua rentabilidade (q) menos o seu risco (r).

6) Sendo i*, a taxa de juros que remunera títulos livres de risco; i, a taxa de juros que remunera títulos domésticos; $\left[\mathrm{d}=\left(\mathrm{E}^{\mathrm{e}}-\mathrm{E}\right) / \mathrm{E}\right]$, o risco de carregamento da moeda doméstica; e $\beta$, o risco de carregamento de títulos domésticos. O retorno total esperado $(\mathrm{RTE}=\mathrm{q}-\mathrm{r}$ ) de cada ativo é apresentado na tabela a seguir. 


\begin{tabular}{|c|c|}
\hline Ativos & $\begin{array}{l}\text { Rentabilidade Total Esperada } \\
\text { (RTE = rentabilidade menos risco) }\end{array}$ \\
\hline 1) Moeda doméstica & $\mathrm{RTE}_{\mathrm{MD}}=0-\mathrm{d}$ \\
\hline 2) Título doméstico & $R T E_{T D}=i-\beta$ \\
\hline 3) Dólar & $\mathrm{RTE}_{\mathrm{D}}=0-0$ \\
\hline 4) Título Livre de Risco & $R T E_{L R}=i^{*}-0$ \\
\hline
\end{tabular}

Nota: Assim como a moeda doméstica é considerada ter poder de compra estável no modelo do capítulo 17 da Teoria Geral, o mesmo é considerado para o dólar em uma economia financeiramente aberta.

7) Em equilíbrio, todos os ativos devem oferecer o mesmo RTE. Então: $\mathrm{RTE}_{\mathrm{MD}}=\mathrm{RTE}_{\mathrm{TD}}=\mathrm{RTE}_{\mathrm{D}}=\mathrm{RTE}_{\mathrm{LR}}$. Não há relevância econômica na análise do equilíbrio entre todos os ativos. São relevantes, entretanto, a análise de equilíbrio entre pares de ativos, tais como nos casos descritos a seguir.

7.1) Caso 1: O caso argentino dos anos 1990. O Plano de Conversibilidade que vigorou na Argentina durante a década de 1990 estabeleceu, na Constituição do país, que a taxa de câmbio era 1 (peso) para 1 (um) dólar americano. Durante alguns anos daquela década, acreditava-se que compor o portfólio com dólares ou com pesos era indiferente. Então,

$$
\begin{aligned}
\mathrm{RTE}_{\mathrm{MD}} & =\mathrm{RTE}_{\mathrm{D}}=0, \\
& 0-\mathrm{d}=0-0=>\mathrm{d}=0
\end{aligned}
$$

é a situação em que não se espera qualquer desvalorização cambial.

7.2) Caso 2: Dois ativos não intercambiáveis. Podem ocorrer situações em que compor o portfólio com títulos domésticos ou com títulos livre de risco seja indiferente. Mas neste caso, diferentemente do caso argentino, os ativos não são intercambiáveis, então:

$$
\begin{aligned}
\mathrm{RTE}_{\mathrm{TD}}= & \mathrm{RTE}_{\mathrm{LR}}, \\
& \mathrm{i}-\beta=\mathrm{i}^{*}-0 \\
& \mathrm{i}-\mathrm{i}^{*}=\beta=>\mathrm{i}=\mathrm{i}^{*}+\beta
\end{aligned}
$$

ou seja, em equilíbrio, o diferencial de juros (doméstico-internacional) é igual ao risco de carregamento de um título doméstico. Em outros termos, a taxa de juros doméstica deveria ser igual à taxa de juros internacional mais o risco de default. Contudo, esses dois ativos não são intercambiáveis, tal como é a moeda doméstica e o dólar americano (caso 1). Então, ao retorno total esperado do título doméstico deveria ser adicionado o retorno total esperado da moeda doméstica, assim como ao retorno total esperado do título livre de risco deveria ser adicionado o retorno total esperado do dólar. Não há como adquirir títulos domésticos com títulos livre de risco e vice-versa (há um trâmite institucional-legal!); então, emerge um novo caso que é apresentado a seguir.

7.3) Caso 3: Mobilidade plena de capitais. Riscos e rentabilidades domésticas, em seu conjunto, devem ser carregados para que haja conversibilidade plena de títulos domésticos em títulos livres de risco. Então, 


$$
\begin{aligned}
\mathrm{RTE}_{\mathrm{MD}}+ & \mathrm{RTE}_{\mathrm{TD}}=\mathrm{RTE}_{\mathrm{D}}+\mathrm{RTE}_{\mathrm{LR}} \\
& 0-\mathrm{d}+\mathrm{i}-\beta=0-0+\mathrm{i}^{*}-0 \\
& \mathrm{i}-\mathrm{i}^{*}=\mathrm{d}+\boldsymbol{\beta}
\end{aligned}
$$

ou seja, em equilíbrio, o diferencial de juros (doméstico-internacional) é igual ao risco de carregamento de um título doméstico mais a expectativa de desvalorização cambial. Logo, o diferencial de taxa de juros é o prêmio pago para o agente abrir mão da segurança do ativo livre de risco que possui. Contudo, há agentes que, embora tenham acesso a dólares, ou não têm interesse, ou por qualquer outro motivo não desejam reter títulos "americanos". Esse é o caso (descrito a seguir) de muitos global players residentes.

7.4) Caso 4: Retenção de dólares. Há agentes econômicos, em geral, de pequeno porte, que não tem acesso a mercados financeiros de títulos livres de risco. O máximo da sofisticação financeira que buscam ao compor seus portfolios é o carregamento de ativos livres de risco, mas que não têm rentabilidade. Transitam de títulos domésticos à aquisição de dólares. Então,

$$
\begin{gathered}
\mathrm{RTE}_{\mathrm{MD}}+\mathrm{RTE}_{\mathrm{TD}}=\mathrm{RTE}_{\mathrm{D}} \\
0-\mathrm{d}+\mathrm{i}-\beta=0-0 \\
\mathrm{i}=\mathrm{d}+\beta
\end{gathered}
$$

ou seja, em equilíbrio, a taxa de juros doméstica é igual ao risco de carregamento de um título doméstico mais a expectativa de desvalorização cambial. Então, a taxa de juros (e não o diferencial neste caso) é o prêmio pago para o agente abrir mão da segurança que o dólar possui.

8) A segurança total e a rentabilidade de títulos "americanos" podem ser trocados (via dólares e, posteriormente, via moeda doméstica) pela menor liquidez dos títulos domésticos; em compensação, o agente troca a segurança e a rentabilidade positiva, mas baixa, de um ativo livre de risco pela rentabilidade mais elevada dos títulos domésticos. Isto pode ser expresso pela seguinte inequação:

$$
\mathrm{RTE}_{\mathrm{TD}}>\mathrm{RTE}_{\mathrm{LR}} \text {, }
$$

mas para que isto ocorra a taxa de juros doméstica descontada da taxa de juros internacional deve compensar o risco atribuído ao carregamento de títulos domésticos somada à desvalorização cambial esperada, ou seja, a rentabilidade (diferencial de juros) deve ser um prêmio capaz de fazer o agente ceder a sua preferência por reter ativos mais líquidos em uma economia financeiramente globalizada, tal como expresso na inequação a seguir:

$$
i-i^{*}>\left[\left(E^{e}-E\right) / E\right]+\beta
$$

9) Quando a rentabilidade total do ativo livre de risco é maior que a do ativo doméstico, haverá venda de ativos domésticos (títulos e moeda) e compra de dólares e títulos livre de risco, o que é expresso pelas seguintes inequações:

$$
\mathrm{RTE}_{\mathrm{LR}}>\mathrm{RTE}_{\mathrm{TD}} \text {, então: }\left[\left(\mathrm{E}^{\mathrm{e}}-\mathrm{E}\right) / \mathrm{E}\right]+\beta>\mathrm{i}-\mathrm{i}^{*} \text {. }
$$

Nesse caso, haverá fuga de capitais e depreciação cambial, caso o banco central não tenha dólares (reservas) suficientes para ofertar. 
10) Mas por que houve esta desigualdade $\left(\mathrm{RTE}_{\mathrm{LR}}>\mathrm{RTE}_{\mathrm{TD}}\right)$, este desequilíbrio? Por que a rentabilidade total esperada do título livre de risco ficou maior que a do título doméstico? Uma das quatro opções ou uma combinação entre elas ocorreu: (i) houve elevação das expectativas de desvalorização cambial; (ii) houve aumento do risco de default; (iii) houve redução na taxa de juros doméstica; (iv) houve elevação da taxa de juros internacional. $\mathrm{Na}$ análise feita a seguir, serão discutidas somente as duas primeiras opções.

11) Os eventos descritos em (i) e em (ii) representariam um movimento de aumento da preferência pela liquidez dos global players que somente poderia ser compensado com uma elevação da taxa de juros doméstica por parte do governo. Contudo, a reação do governo influenciaria, provavelmente, de forma adversa a preferência pela liquidez dos global players: a elevação da taxa de juros poderia elevar o risco de default (ver, por exemplo, Bresser-Pereira e Nakano, 2002), o que faria aumentar a fuga de capitais, que por sua vez faria aumentar a taxa de desvalorização cambial esperada - assim, a elevação da taxa de juros poderia não ser suficiente para compensar o aumento do risco de default e a intensificação das expectativas de desvalorização cambial que poderiam se tornar autônomas, ou seja, seriam explicadas por si mesmas. Cabe ser ressaltado que embora a elevação da taxa de juros não tenha sido suficiente para conter a fuga de capitais, tal elevação da taxa de juros seria explicada pelo aumento da preferência por liquidez. E a fuga de capitais foi (é) a forma como os agentes exerceram (exercem) uma maior preferência pela liquidez.

12) Assim como Keynes, no modelo de economia fechada da Teoria Geral, não confiava na política monetária como um bom instrumento de controle da demanda agregada porque a preferência pela liquidez podia mudar em sentido adverso e anular as ações monetárias, o mesmo pode ser dito relativamente à política monetária, em uma economia pequena e financeiramente aberta, como um instrumento adequado para controlar o nível ou reduzir a volatilidade da taxa de câmbio. Sob condições específicas, em uma economia fechada, é mantida por parte do governo a capacidade de determinação da taxa de juros e de controle da demanda agregada com o uso da política monetária (ver Sicsú, 2001); já em uma economia pequena e financeiramente integrada, além da perda de autonomia da política monetária, verifica-se sua ineficácia. A perda de autonomia ocorre porque a desvalorização cambial, decorrente de um aumento da preferência pela liquidez, é sempre considerada inaceitável por parte do governo, assim como a quantidade de reservas é sempre insuficiente nos períodos críticos, exatamente nos momentos em que são mais necessárias.

13) Em uma economia fechada, quando há um aumento da preferência pela liquidez, o governo pode deixar a taxa de juros subir ou pode aumentar a oferta do ativo plenamente líquido, a moeda. Numa economia pequena e financeiramente aberta, a capacidade do governo de ofertar o ativo plenamente líquido (reservas em dólares) é limitada, tal como foi demonstrado, por exemplo, pela experiência internacional durante os anos 1990. A conclusão lógica é que o governo perde autonomia para decidir a taxa de juros se objetiva neutralizar os efeitos resultan- 
tes sobre a taxa de câmbio de decisões relativas ao aumento de preferência pela liquidez - os governos tentam, ainda que esta tarefa de conter a desvalorização cambial abrupta com a elevação da taxa de juros seja sabidamente uma tarefa inglória.

\section{TOUROS, URSOS E AS TAXAS DE CÂMBIO E JUROS}

14) No mercado financeiro, um agente touro é comprador de títulos, um agente urso é vendedor. O primeiro quer obter ganhos de capital, o segundo quer evitar perdas de capital. No mercado global, touros adquirem títulos domésticos; e ursos, dólares para poder adquirir títulos livre de risco. Enquanto numa economia fechada, touros compram títulos porque esperam uma queda da taxa de juros, o que implica obter ganhos de capital (se títulos são perpétuos); em uma economia pequena e financeiramente integrada (considerando o risco de default desprezível para um termo muito curto), touros adquirem títulos se não esperam uma desvalorização que seja maior do que o diferencial de taxa de juros em determinado período, o que imporia uma perda de capital. Ursos, sob as mesmas condições, avaliam que haverá uma desvalorização superior ao diferencial de taxa de juros em um determinado período capaz de impor perdas de capital, assim vendem os títulos domésticos que possuem e buscam abrigo nos ativos estrangeiros. Enquanto touros vendem dólares para comprar moeda doméstica e, posteriormente, títulos, ursos vendem títulos para obter moeda doméstica e, posteriormente, comprar dólares.

15) A taxa de câmbio será influenciada, portanto, pelas decisões desses dois grupos (ursos e touros). Será influenciada e não determinada, porque dólares circulam na esfera "financeira global" e na esfera "industrial global" de um país. Em outras palavras, dólares são negociados não apenas por ursos e touros, mas também por importadores, exportadores, investidores em bens de capital etc. Tal como em uma economia fechada, o ativo plenamente líquido em uma economia aberta circula em duas esferas: a industrial e a financeira (segundo o jargão estabelecido por Keynes no seu Tratado sobre a Moeda). ${ }^{1}$

16) Quando predominam ursos na circulação "financeira global”, a taxa de câmbio tende a se desvalorizar. Quando predominam touros, tende a haver uma

\footnotetext{
${ }^{1}$ Em uma economia fechada, agentes econômicos realizam transações em uma economia monetária que pode ser sinteticamente definida como uma economia de duas esferas de circulação da moeda: a industrial e a financeira (Keynes, CWJMK, v. 5, pp. 217-30). Na primeira, a moeda exerce sua função de meio de troca, faz girar bens e serviços. O produto real, o nível de preços e a velocidade-renda do meio de troca determinam o volume de moeda que satisfaz as necessidades dos agentes que atuam nessa esfera. Na segunda, a moeda faz girar ativos financeiros — papéis que possuem uma diversidade de graus de liquidez, exigem diferentes custos de manutenção e podem gerar diferenciados ganhos de juros e ganhos de capital. Nesta última esfera de circulação, a própria moeda se transforma em um ativo, com segurança máxima e rentabilidade nula.
} 
valorização da taxa de câmbio. Portanto, em uma economia pequena e financeiramente integrada, touros e ursos ganham força para determinar a taxa de câmbio e, por conseguinte, a taxa de juros - já que os governos sofrem de fear of floating e os estoques de reservas que seus bancos centrais possuem são limitados. Assim, a taxa de juros, tal como em uma economia fechada, dependerá também das reações desses grupos. Contudo, em uma economia aberta, ocorrerá pelo preço do dólar (ou seja, via taxa de câmbio). Supõe-se que o banco central, em uma economia fechada, possua uma quantidade de títulos suficiente para determinar o seu preço e, conseqüentemente, a taxa de juros. Supõe-se que o banco central, em uma economia aberta, não possui uma quantidade suficiente de dólares capaz de neutralizar as ações de ursos; e, portanto, de manter a sua capacidade determinar a taxa de câmbio e, conseqüentemente, de manter a autonomia pública de determinação da taxa de juros. No caso de predomínio de touros, bastaria a um banco central (que objetiva estabilizar a taxa de câmbio) enxugar os dólares entrantes e promover uma esterilização da monetização - contudo, a esterilização pode elevar demasiadamente a dívida pública, dependendo do nível da taxa de juros doméstica.

17) Em uma economia pequena e financeiramente integrada, as expectativas de agentes touros e ursos que atuam no mercado de divisas estão baseadas em uma taxa normal de câmbio (análoga à taxa de juros normal descrita por Keynes). Quando as expectativas para uma grande parte dos agentes são de que a taxa de câmbio de mercado é muito baixa em relação a sua taxa de câmbio normal e que esta diferença é percentualmente maior do que a diferença entre a taxa de juros doméstica e a internacional, o mercado estará composto de forma predominante por ursos. O resultado provável será uma fuga de capitais e uma, possível, crise cambial.

18) Quando o preço do mercado cambial é muito volátil, mais voláteis tendem a ser as taxas consideradas normais desse mercado, portanto, voláteis tendem a ser as expectativas, particularmente, em momentos de crise. No mercado cambial, a experiência internacional tem demonstrado que crises de desvalorização (trajetória abrupta e ascendente do preço da moeda estrangeira) correspondem a períodos de aumento da volatilidade da taxa de câmbio (esta relação está demonstrada para o caso brasileiro em Sicsú, 2002).

\section{SUMÁRIO}

O modelo adaptado da Teoria Geral preserva o resultado básico do modelo original de 1936, qual seja: a taxa de juros é o prêmio pago aos agentes para abrir mão da liquidez que possuem. Aumentos da taxa de juros, em momentos de crises cambiais, tendem a não ser eficientes para compensar os aumentos da preferência pela liquidez que se acentuam drasticamente nestes períodos. Portanto, além de governos perderem autonomia para determinar a taxa de juros se não aceitam uma flutuação pura da taxa de câmbio, a política monetária torna-se ineficaz na medida em que uma elevação da taxa de juros faz aumentar a preferência pela 
liquidez porque faz aumentar o risco default da dívida pública. Enquanto Keynes, em uma economia fechada, via com reservas a política monetária como um instrumento capaz de controlar o emprego e o produto; deve-se observar com reservas, em uma economia pequena e financeiramente aberta, a capacidade desta mesma variável de ser capaz de controlar a taxa de câmbio. As crises cambiais-financeiras dos anos 1990 demonstraram a fraqueza da taxa de juros como instrumento de estabilização.

\section{REFERÊNCIAS BIBLIOGRÁFICAS}

BRESSER-PEREIRA, L.C. e NAKANO, Y. (2002). Uma estratégia de desenvolvimento com estabilidade. Revista de Economia Política, 22(3): 146-180.

SICSÚ, J. (2002). Flutuação Cambial e Taxa de Juros no Brasil. Revista de Economia Política, 22(3): 132-37.

SICSÚ, J. (2001). Credible Monetary Policy: a Post Keynesian approach. Journal of Post Keynesian Economics, 23(4), Summer: pp. 669-87. Estados Unidos.

KEYNES, J. M. (CWJMK), (1971-83). The Collected Writings of John Maynard Keynes. Londres: Macmillan - O volume da coleção é mencionado com a notação CWJMK seguida de seu número. 